\title{
ASO Author Reflections: Despite Medicaid Expansion, Large Disparities in Breast Reconstruction Persist
}

\author{
Justin Le Blanc, $\mathrm{MD}^{1}$, Tristen Park, $\mathrm{MD}^{2}$, and Donald Lannin, $\mathrm{MD}^{3}$ \\ ${ }^{1}$ Yale University, New Haven; ${ }^{2}$ Yale School of Medicine, New Haven; ${ }^{3}$ Department of Surgery, Yale New Haven Breast \\ Center, New Haven
}

\section{PAST}

It has been recognized for many years that disparities in the use of breast reconstruction exist based on race, income, education, health insurance, geographic region, and whether the patient is treated at an academic medical center. ${ }^{1}$ The Affordable Care Act (ACA) sought to address some of these disparities by expanding Medicaid coverage to patients at or below $138 \%$ of the federal poverty limit. This has led to markedly reduced numbers of uninsured patients in the states that participated in the program, and also has resulted in better access to screening and prevention practices, reduced infant mortality, better trauma care, and reduced late-stage presentation of breast cancer. ${ }^{2}$ It has not been known, however, whether this has led to a decrease in the disparities regarding breast reconstruction.

\section{PRESENT}

Two recent articles in Annals of Surgical Oncology address this issue with somewhat conflicting results. Ramalingam et al. $^{3}$ looked individually at disparities in reconstruction caused by race, income, and education and found slightly reduced racial disparity in expansion states with time. They also found that after expansion, the lowest quartile for income and education approached the reconstruction rate of the second lowest quartile. Therefore, they concluded that Medicaid expansion had contributed to a slight reduction in disparities.

(C) Society of Surgical Oncology 2021

First Received: 7 October 2021

Accepted: 7 October 2021;

Published Online: 21 October 2021

J. Le Blanc, MD

e-mail: justin.leblanc@yale.edu
Le Blanc et al. ${ }^{4}$ used a more global approach and showed that reconstruction rates were much higher in expansion states than in non-expansion states, both before and after Medicaid expansion. Large preexisting differences existed between expansion and non-expansion states with regard to race, income, education, payor status, tumor stage, geographic region, and number of academic medical centers. In a multivariate model, all these factors, but not Medicaid expansion itself, contributed to the difference in reconstruction rates.

\section{FUTURE}

For many reasons, Medicaid expansion is clearly a step in the right direction. However, whether a reduction of disparities in breast reconstruction confers a minor benefit or not, it is clear from both articles that a large gap in reconstruction rates remains between advantaged and disadvantaged populations. Much further work is required to address these disparities.

\section{REFERENCES}

1. Chiu AS, Thomas P, Killelea BK, Horowitz N, Chagpar AB, Lannin DR. Regional variation in breast cancer surgery: results from the National Cancer Database (NCDB). Am J Surg. 2017;214:907-13.

2. Le Blanc JM, Heller DR, Friedrich A, Lannin DR, Park TS. Association of Medicaid expansion under the Affordable Care Act with breast cancer stage at diagnosis. JAMA Surg. 2020;155:752-8.

3. Ramalingam K, Ji L, Pairawan S, Molina DC, Lum SS. Improvement in breast reconstruction disparities following Medicaid expansion under the Affordable Care Act. Ann Surg Oncol. 2021;28:5558-67.

4. Le Blanc J, Golshan M, Lannin DR, et al. Association of Medicaid expansion with post-mastectomy reconstruction rates. Ann Surg Oncol. 2021. https://doi.org/10.1245/s10434-021-10858-6.

Publisher's Note Springer Nature remains neutral with regard to jurisdictional claims in published maps and institutional affiliations. 